\title{
Testing of a Radiant Wall Cooling System with Pipes Coupled to Aerated Blocks
}

\author{
Martin Šimko1*, Dušan Petráš, Michal Krajčík, Daniel Szabó1 \\ ${ }^{1}$ Faculty of Civil Engineering, Slovak University of Technology in Bratislava, 81005 Bratislava, Radlinského 2766/11, Slovakia \\ * Corresponding author, e-mail: martin.simko@stuba.sk
}

Received: 08 June 2021, Accepted: 21 September 2021, Published online: 09 December 2021

\begin{abstract}
Thermal output, surface temperatures, and supply and return water temperature were measured for a wall cooling system involving pipe attached to a wall section made of thermally insulating blocks. The experiment was performed for warm climatic conditions typical of, e.g., summer in Central and Northern Europe. The outdoor environment was simulated by a climatic chamber while the indoor climate was simulated by attaching a hotbox to the wall surface. The sensitivity of thermal output to several design parameters was investigated by 2D numerical simulations. The measurements showed a fast thermal response of the wall system. The cooling output was $38.3 \mathrm{~W}$ per $\mathrm{m}^{2}$ of the cooling area which equalled about $4.8 \mathrm{~W} / \mathrm{m}^{2}$ per $1 \mathrm{~K}$ temperature difference between water and hotbox. The lowest surface temperature of $19.6^{\circ} \mathrm{C}$ was measured at the pipe. Thus, the cooling output could be enhanced by reducing the surface temperature closer to the dew point temperature. The temperature of water in the pipe was very close to the surface temperature. It was illustrated how this characteristic of the wall cooling system tested positively affects the efficiency and cooling capacity of an air-to-water heat pump.
\end{abstract}

\section{Keywords}

radiant cooling, radiant wall system, thermal output, parametric simulations

\section{Introduction}

One of the key global problems in the $21^{\text {st }}$ century is climate change and the resulting weather instability and hotter summers. Consequently, space cooling is becoming a major energy consumer even in regions where space heating has traditionally been the dominant energy enduse. The cooling load can be covered by a convective or a radiant cooling system [1-3]. An important advantage of radiant systems is their suitability for integration with renewable energy sources [4, 5]. Promising technical solutions that could reduce the environmental impacts include the combination of the radiant system with a ground heat exchanger [5, 6], heat pump [7-9] or solar cooling system [10-12].

In certain situations, wall cooling systems can be preferable to the more frequently used floors and ceilings. In an insulated building with mechanical ventilation, a wall section may be enough to create thermal comfort $[13,14]$. Compared to cooling floors, wall systems can be more suitable for building retrofit because they do not reduce the story height and can be easily attached to existing structures. Radiant walls have a higher cooling capacity per surface area than floors $\left(70 \mathrm{~W} / \mathrm{m}^{2}\right.$ as compared to $40 \mathrm{~W} \mathrm{~m}^{2}$ ) [3]. Besides, wall cooling can lead to a more homogeneous distribution of room temperature and reduce the risk of thermal discomfort due to cold floors $[15,16]$.

Previous studies showed that a particular design involving pipes attached to an insulated thermal core has certain advantages such as high thermal output, ease of control, and affordability [17, 18]. This design can be used both for heating and cooling and can be applied on both walls and ceilings. However, detailed information about the thermal performance of this wall system is lacking. The thermal performance of a wall cooling system involving a pipe attached to a wall section made of thermally insulating blocks was therefore tested using climate chambers and a hotbox. Heat flux and surface and water temperatures were measured for a representative cooling situation. The sensitivity of the thermal output to several design parameters was investigated by $2 \mathrm{D}$ numerical simulations of heat transfer in the wall. 


\section{Heat exchange coefficient between surface and space}

The relationship between heat flow density and mean differential surface temperature depends on the type of emitting surface (floor, wall, ceiling) and the surface temperature relative to the room temperature (heating or cooling) [3]. The heat exchange coefficient is the parameter that affects the amount of heat transferred between the surface and space. For radiant wall systems, the default value of the heat exchange coefficient is $8 \mathrm{~W} /\left(\mathrm{m}^{2} . \mathrm{K}\right)$ [19]. Using this value, the thermal output of a wall system is determined from the Eq. (1):

$q=8 \cdot\left(\left|T_{a i}-T_{S, m}\right|\right)$,

where $T_{a i}$ is the room operative temperature $\left({ }^{\circ} \mathrm{C}\right)$ and $T_{S, m}$ is the average surface temperature $\left({ }^{\circ} \mathrm{C}\right)$. For sensible cooling, the ceiling has a capacity of up to $100 \mathrm{~W} / \mathrm{m}^{2}$ whereas the wall has a capacity of about $70 \mathrm{~W} / \mathrm{m}^{2}$. Acceptable surface temperatures to avoid thermal discomfort and the risk for condensation, and typical values of the heat exchange coefficient between radiant surface and room are shown in Table 1 [3].

The heat exchange coefficient between surface and space also depends on the location of pipes in the structure, pipe spacing, and differential temperature [3]. Fig. 1 shows examples of walls with different locations of the pipe in the structure. Type $\mathrm{A}$ is a wall with the pipe in inner plaster insulated from the exterior by thermal insulation. Type B represents a wall with pipes in thermal insulation located between wall structure and inner plaster [3].

Type $C$ in Fig. 1 represents a wall system with pipes arranged in a massive concrete slab and Type D is a wall with pipe arranged in inner plaster coupled to the thermal core. Construction of the wall Type D is similar to the radiant wall cooling system investigated in this study.

The heat flux density $q$ at a surface depends on the parameters such as pipe spacing $T$, thickness $s_{u}$, and thermal conductivity $\lambda_{E}$ of the layer inward of the pipe, pipe external diameter $D=d_{a}$, and the thermal conductivity of the pipe $\lambda_{R}$. These parameters are explained in Fig. 1 (Type C).

As an example of the influence of the design parameters on the heat flux density, Fig. 2 [3] shows the heat exchange for wall radiant system Type A expressed as the function of differential temperature and pipe spacing, where $\Delta \Theta_{H}$ is heating/cooling medium differential temperature. The limit curve in Fig. 2 represents the maximum cooling capacity of the wall system and $R_{\lambda, B}\left(\left(\mathrm{~m}^{2} \cdot \mathrm{K}\right) / \mathrm{W}\right)$ is the thermal resistance of surface covering assumed in the calculation [3].
The heat flux between embedded pipes (heating or cooling medium) and space or surface is calculated using thermal resistances. These thermal resistances can be determined by calculation or by testing. The concept is shown in Fig. 3 [3].

Table 1 Total heat exchange coefficient between surface and space, acceptable surface temperature and capacity for heating/cooling [3]

\begin{tabular}{ccccccc}
\hline & $\begin{array}{c}\text { Total heat exchange } \\
\text { coefficient }\left(\mathrm{W} / \mathrm{m}^{2} . \mathrm{K}\right)\end{array}$ & $\begin{array}{c}\text { Acceptable surface } \\
\text { temperature }\left({ }^{\circ} \mathrm{C}\right)\end{array}$ & $\begin{array}{c}\text { Maximum } \\
\text { capacity }\left(\mathrm{W} / \mathrm{m}^{2}\right)\end{array}$ \\
\hline Heat. & Cool. & Heat. & Cool. & Heat. & Cool. \\
\hline Wall & 8 & 8 & $\sim 40$ & 17 & 160 & 72 \\
\hline
\end{tabular}

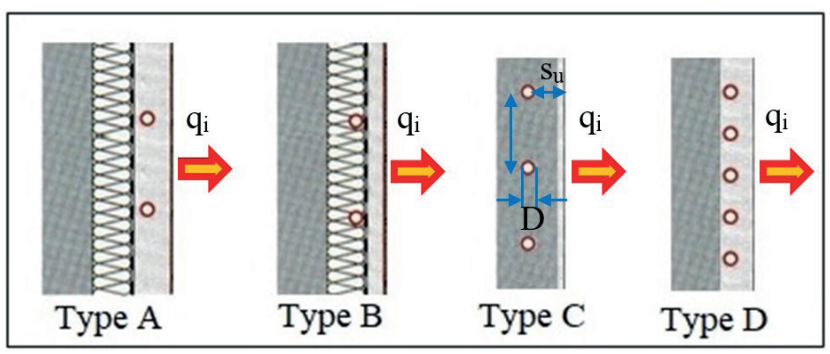

Fig. 1 Walls with different locations of pipe in the structure [3]

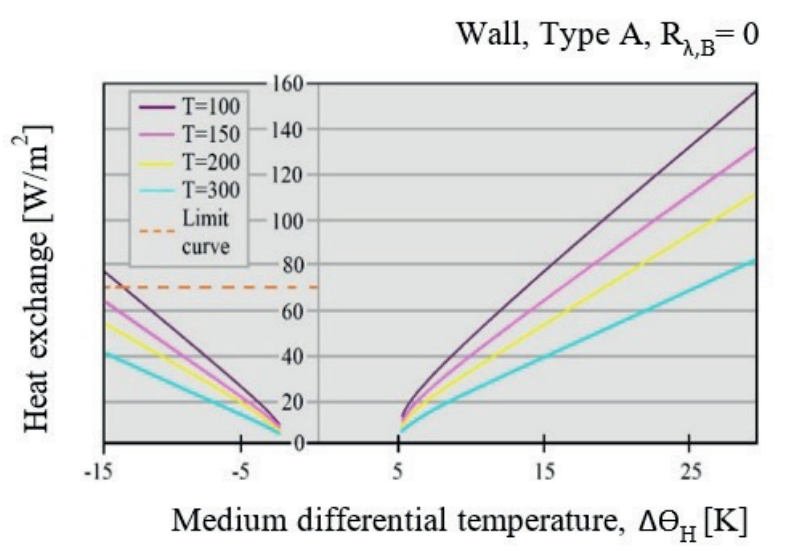

Fig. 2 Heat exchange for wall system expressed as the function of differential temperature and pipe spacing [3]

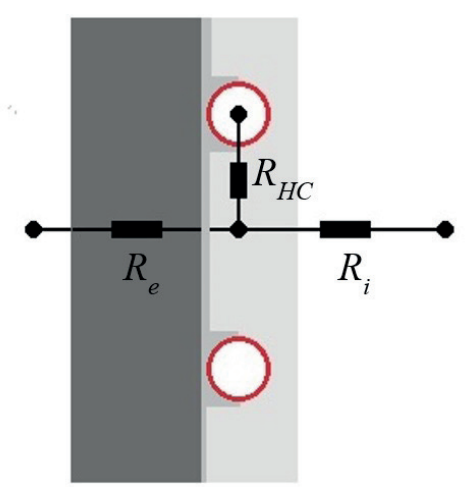

Fig. 3 Heat transfer resistance network through the wall structure, simplified network of three thermal resistances [3] 
The thermal output to the room is described as follows [3]:

$$
\begin{aligned}
& q_{i}=K_{H} \cdot \Delta \theta_{H}, \\
& K_{H}=1 /\left(R_{H C}+R_{i}\right),
\end{aligned}
$$

where $q_{i}$ is thermal output to the room $\left(\mathrm{W} / \mathrm{m}^{2}\right) ; \Delta \Theta_{H}$ is the heating/cooling medium differential temperature $(K)$; $K_{H}$ is equivalent heat transmission coefficient $\left(\mathrm{W} /\left(\mathrm{m}^{2} . \mathrm{K}\right)\right.$ ); $R_{H C}$ is equivalent resistance between the medium and fictive core or heat conduction layer $\left(\left(\mathrm{m}^{2} . \mathrm{K}\right) / \mathrm{W}\right)$; and $R_{i}$ is thermal resistance above the heat/conducting layer, e.g., from the heat-conducting plate to the conditioned room $\left(\left(\mathrm{m}^{2} . \mathrm{K}\right) / \mathrm{W}\right)$; Re is thermal resistance beneath the heat-conducting layer, from the heat-conducting plate to a neighbour room or the outdoor air $\left(\left(\mathrm{m}^{2} . \mathrm{K}\right) / \mathrm{W}\right)[3]$.

\section{Experimental setup}

\subsection{Experimental system}

The system studied was a wall section that represented an outer perimeter wall consisting of aerated concrete masonry $200 \mathrm{~mm}$ thick and thermal insulation $100 \mathrm{~mm}$ thick. A higher masonry and insulation thickness would have only a small effect on the thermal performance of the wall system [20]. The dimensions of the wall section were $1200 \mathrm{~mm} \times 1200 \mathrm{~mm}$. The pipe was placed in the interior plaster and pipe spacing was $100 \mathrm{~mm}$.

\subsection{Location of the sensors}

The surface temperature was monitored using PT100 resistance thermometers type CRZ2005100A-1-Ni placed at selected locations along the experimental wall, as shown in Fig. 4 [20].

The temperature sensors were classified into accuracy class 1 and their accuracy was variable in the range $\pm(0.15+0.002 \times t){ }^{\circ} \mathrm{C}$. At points A to $\mathrm{D}$, the temperature was recorded at four depths to obtain cross-sectional temperature profiles. The heat flux was monitored by a thermopile sensor type FQA017CSI for the study of radiation and convective heat flux with an accuracy level in the range of $\pm 5 \%$ of the value measured [20].

\subsection{Climatic chambers and hotbox}

The experimental wall was built into a partition wall that divided two climatic chambers with controlled air temperature and humidity. One chamber simulated the indoor environment, whereas the other simulated the climatic

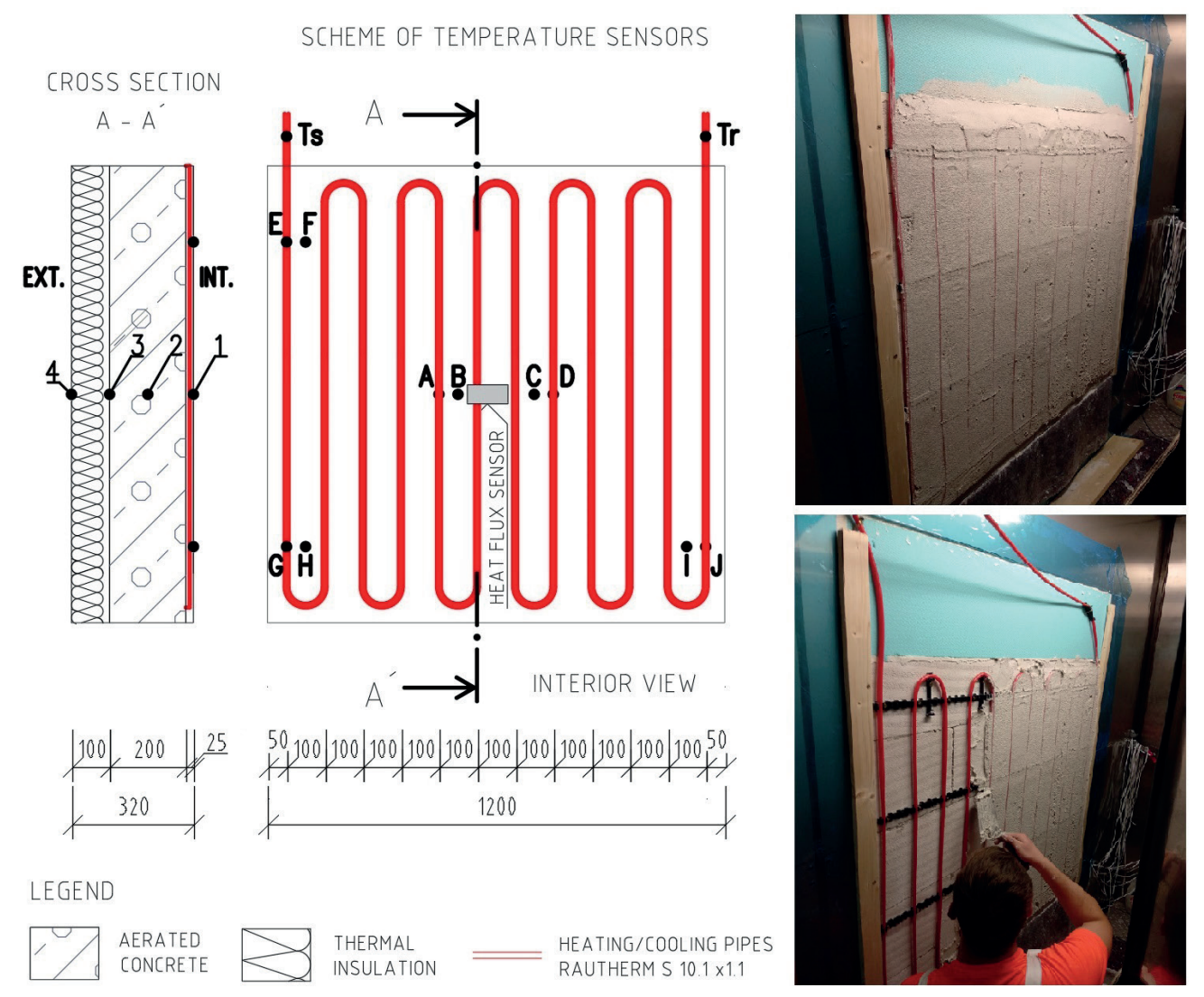

Fig. 4 Location of sensors and photo of the active layer of the experimental wall [20] 
conditions. The airflow in the climatic chambers was ensured by fans. To create the desired conditions, a hotbox with precise air temperature control was attached to the inner surface of the experimental wall [20].

\subsection{Testing of the wall system in cooling mode}

The following boundary conditions were set: air temperature in the chamber simulating the outdoor environment was $T_{a, e}=40^{\circ} \mathrm{C}$, air temperature in the hotbox (HB) was $T_{a, i}=26^{\circ} \mathrm{C}$, and the water temperature in the pipes was $T_{w}=18{ }^{\circ} \mathrm{C}$. The measurements started on 25 February 2020 at 8:04 pm and the cooling system was started on 26 February 2020 at 7:12 pm. The wall surface temperatures were measured at selected points $A-1, B-1, C-1, D-1$. Supply and return water temperatures were measured as well $\left(T_{s}, T_{r}\right)$ as shown in Fig. 4 [21].

\section{Numerical model of the radiant wall system}

Two-dimensional stationary simulations were performed to investigate the sensitivity of the thermal output to some of the design parameters and boundary conditions.

\subsection{Physical model of the wall}

Fig. 5 shows the physical model of the wall section with material characteristics and thermophysical properties of the wall materials.

\subsection{Stationary simulations}

The results were obtained by solving a set of equations of two-dimensional heat transfer by conduction, using a dedicated CalA software [22, 23]. The calculation was based on a detailed numerical solution of a two-dimension stationary temperature field by the method of rectangle-shaped control volumes, each representing a single temperature [24]. The distribution of the temperature in the Cartesian coordinate system was described by the Fourier equation of thermal diffusion:

$\frac{\partial}{\partial x}\left(\lambda \frac{\partial T}{\partial x}\right)+\frac{\partial}{\partial y}\left(\lambda \frac{\partial T}{\partial y}\right)+S=\rho . c \cdot \frac{\partial T}{\partial \tau}$,

where $T$ is the temperature $(\mathrm{K}) ; S$ is an internal heat source $\left(\mathrm{W} / \mathrm{m}^{3}\right) ; \tau$ is time $(\mathrm{s}) ; \lambda$ is thermal conductivity $(\mathrm{W} /(\mathrm{m} . \mathrm{K}))$; $\rho$ is bulk density $\left(\mathrm{kg} / \mathrm{m}^{3}\right)$; and $c$ is the specific heat capacity at a constant pressure (J/(kg.K)) [22, 23].

The thermophysical properties of the materials were considered to be constant, isotropic, and temperature-independent in all simulations. The boundary conditions defining the specific heat flux on the surface of

\begin{tabular}{|c|c|c|c|c|c|}
\hline \multirow[t]{2}{*}{$\begin{array}{l}\text { - External plaster } \\
\text { - TI - Styrodur } \\
\text { - Aerated bricks } \\
\text { - Pipes } 10.1 \times 1.1 \\
\text { - Inner plaster }\end{array}$} & $\begin{array}{l}0.01 \mathrm{~m} \\
0.1 \mathrm{~m} \\
0.2 \mathrm{~m} \\
\\
0.025 \mathrm{~m}\end{array}$ & Material & $\begin{array}{l}\text { Bulk } \\
\text { density } \\
\rho \\
\mathrm{kg} / \mathrm{m}^{3}\end{array}$ & $\begin{array}{c}\text { Heat } \\
\text { conductivity } \\
\lambda \\
\mathrm{W} /(\mathrm{m} . \mathrm{K})\end{array}$ & $\begin{array}{c}\text { Specific } \\
\text { heat } \\
\text { capacity } \\
\text { C } \\
\mathrm{J} /(\mathrm{kg} \cdot \mathrm{K})\end{array}$ \\
\hline & & $\begin{array}{l}\text { thermal } \\
\text { insulation }\end{array}$ & 17 & 0.035 & 1270 \\
\hline & . & $\begin{array}{l}\text { aerated } \\
\text { bricks }\end{array}$ & 600 & 0.19 & 1000 \\
\hline & b & $\begin{array}{l}\text { inner plaster } \\
\text { external plaster }\end{array}$ & $\begin{array}{l}1300 \\
1600\end{array}$ & $\begin{array}{l}0.7 \\
0.8\end{array}$ & $\begin{array}{l}840 \\
840\end{array}$ \\
\hline & p & $\begin{array}{l}0 \text { cooling } \\
\text { pipes }\end{array}$ & 1200 & 0.35 & 1000 \\
\hline
\end{tabular}

Fig. 5 Physical model of the wall and material properties. TI - thermal insulation

the computational domain were calculated according to Newton's law of cooling (Eq. 5), assuming adiabatic wall section boundaries (Eq. 6):

$-\lambda .\left(\frac{\partial T}{\partial n}\right)_{W}=h \cdot\left(T_{w}-T_{f}\right)$,

$-\lambda \cdot\left(\frac{\partial T}{\partial n}\right)_{W}=0$

where $w$ is an index indicating the surface of the object; $f$ is an index indicating the surrounding fluid index; $n$ is an index indicating the vertical direction to the surface; and $h$ is the heat transfer coefficient $\left(\mathrm{W} /\left(\mathrm{m}^{2} . \mathrm{K}\right)\right)$, including convection and heat radiation from the radiant surface to the environment $[22,23]$. The default convective heat transfer coefficient between water and pipe was considered to be $1000 \mathrm{~W} /\left(\mathrm{m}^{2} . \mathrm{K}\right)$.

The effects of wind and rain were not explicitly considered. With respect to the higher level of thermal insulation, ignoring climatic conditions was assumed to have a small impact on the applicability of the results. The effect of solar radiation can be expressed through sol-air temperature $\left(T_{\text {sol-air }}\right)$. The sol-air temperature can be interpreted as the outside air temperature which, in the absence of solar radiation, would give the same temperature distribution and rate of heat transfer through a wall as exists due to the combined effects of the actual outdoor temperature distribution plus the incident solar radiation. It is calculated as follows $[22,25]$ :

$T_{\text {sol-air }}=T_{a m b}+(\alpha . \operatorname{Ig}) / h e-(\varepsilon . R) / h e$,

where $T_{a m b}$ is the ambient temperature, i.e., the outside air temperature $\left({ }^{\circ} \mathrm{C}\right) ; \alpha$ is the absorptance of surface for solar radiation $(-) ; I_{g}$ is the total solar radiation incident on surface $\left(\mathrm{W} / \mathrm{m}^{2}\right) ; h_{e}$ is the coefficient of heat transfer by longwave radiation and convection at outer surface $\left(\mathrm{W} /\left(\mathrm{m}^{2} . \mathrm{K}\right)\right)$; 
$\varepsilon$ is the hemispherical emittance of surface $(-) ; \Delta R$ is difference between long-wave radiation incident on surface from sky and surroundings and radiation emitted by blackbody at outdoor air temperature $\left(\mathrm{W} / \mathrm{m}^{2}\right)[22,25]$.

Fig. 6 shows an interpretation of the air temperature in the climatic chamber simulating the outdoor environment $\left(T_{a, e}\right)$ in terms of sol-air temperature at variable solar radiation on the wall $\left(I_{g}\right)$. The air temperature on the interior side of the wall was $26^{\circ} \mathrm{C}$.

\section{Results and discussion}

\subsection{Results of experimental measurements}

Fig. 7 [20] shows the course of supply and return water temperatures, surface temperatures at points $A-1, B-1, C-1$, $D-1$, and heat flux at the inner side of the wall. In steady state, the heat flux reached a value of $38.3 \mathrm{~W} / \mathrm{m}^{2}$. The corresponding supply water $\left(T_{s}\right)$ and surface temperature $\left(T_{\text {surf }, A-D}\right)$ was $17.9^{\circ} \mathrm{C}$ and $21^{\circ} \mathrm{C}$, respectively. This shows

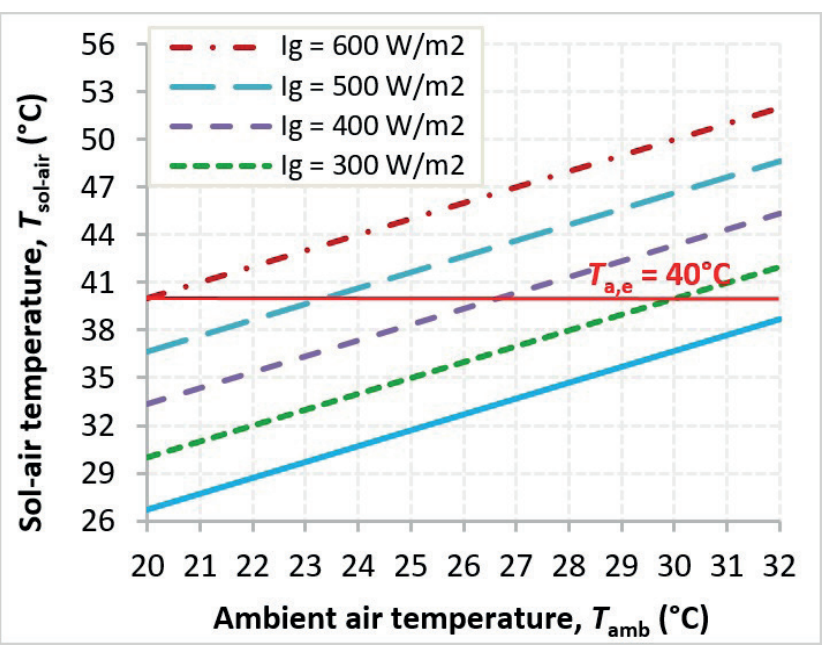

Fig. 6 Interpretation of air temperature on the external side of the wall $\left(T_{a, e}\right)$ in terms of sol-air temperature at variable solar radiation on the wall $\left(I_{g}\right)$

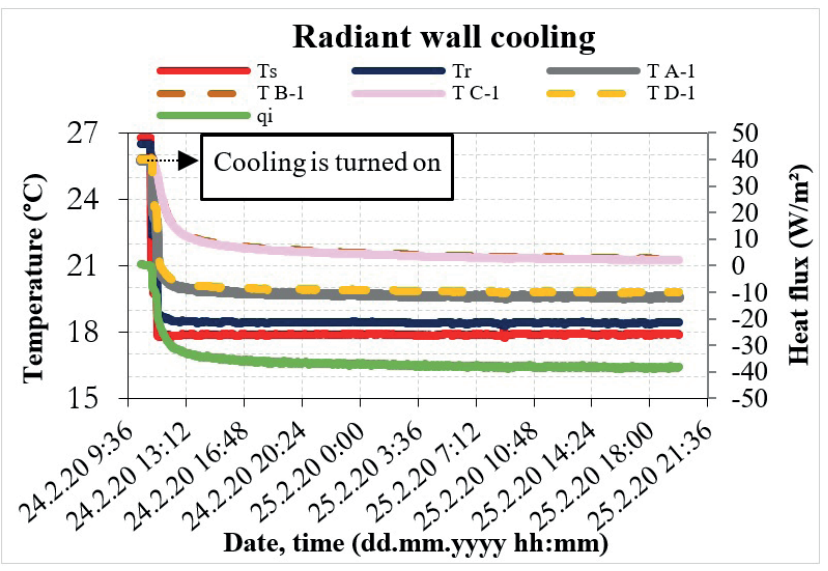

Fig. 7 The course of surface temperatures and heat flux at $T_{a, e}=40{ }^{\circ} \mathrm{C}[20]$ that the thermal output of the wall could be enhanced by further decreasing the wall surface temperature down to the dew point temperature. However, the surface temperature at point $\mathrm{A}$ at the pipe $\left(T_{\text {surf.A }}\right)$ was about $1{ }^{\circ} \mathrm{C}$ lower than the average $\left(T_{\text {surf,A-D}}\right)$. This should be considered to avoid the risk of condensation on the wall surface [20].

The heat exchange coefficient $h_{i}$ depended in particular on the air velocity at the cooling surface. The value derived from the experimental measurement was $7.0 \mathrm{~W} /\left(\mathrm{m}^{2} . \mathrm{K}\right)$. This value can be considered to be low but realistic.

\subsection{Results of parametric simulations}

The stationary simulations were performed for warm climatic conditions. They were focused on the effect of individual parameters on the heat flux. Fig. 8 shows the effect of sol-air temperature on heat flux. The blue curve represents the heat flux to the room and the red curve represents the heat flux to the exterior. The effect of the sol-air temperature on the heat exchange between wall and room is negligible, and its effect on the heat exchange between wall and exterior is relatively small due to the high thermal resistance of the wall.

The parametric simulations also showed the substantial influence of hi on the heat exchange between wall and room. An increase in hi by $1 \mathrm{~W} /\left(\mathrm{m}^{2} . \mathrm{K}\right)$ resulted in an increase in the thermal output by $3.4 \mathrm{~W} / \mathrm{m}^{2}$ for hi in the range between 6 and $14 \mathrm{~W} /\left(\mathrm{m}^{2} . \mathrm{K}\right)$. The heat exchange coefficient between wall and exterior he had virtually no effect on the thermal output of the wall system because of the high level of thermal insulation.

Fig. 9 shows the effect of room temperature on the heat flux. The room temperature has almost no effect on the thermal losses, however, its effect on the thermal output is very important. A rise of the room temperature by $1{ }^{\circ} \mathrm{C}$ increases the thermal output by $7.2 \mathrm{~W} / \mathrm{m}^{2}$. For example, at room temperature of $20{ }^{\circ} \mathrm{C}$, the output is about $5 \mathrm{~W} / \mathrm{m}^{2}$, but it rises to $69.9 \mathrm{~W} / \mathrm{m}^{2}$ at the room temperature of $29^{\circ} \mathrm{C}$.

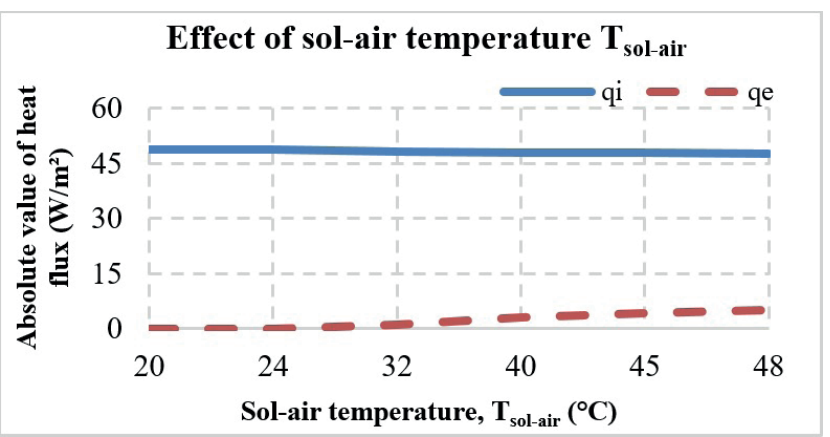

Fig. 8 Effect of sol-air temperature on heat flux 
For radiant heating and cooling systems, the cooling output is controlled by the "self-control" effect meaning that a small decrease in room temperature will significantly decrease the temperature difference between wall and space and thus the cooling output of the wall.

As shown in Fig. 10, the heat exchange coefficient between water and pipe $\left(h_{\text {water }}\right)$ has almost no influence on the heat flux at the inner and outer side of the wall in the range between 1000 to $14000 \mathrm{~W} /\left(\mathrm{m}^{2} . \mathrm{K}\right)$.

It should be noted that in the present study, the effect of pipe spacing on the thermal output was not explicitly considered. A previous study [26] showed that pipe spacing has a significant effect on cooling output. The value of 10 $\mathrm{cm}$ used in this study was considered to be representative.

Fig. 11 shows the cooling output of the radiant wall system for various areas of the cooling surface and room temperature of $26^{\circ} \mathrm{C}$. For example, the cooling output of the wall system with a mean water temperature of $18{ }^{\circ} \mathrm{C}$ is $48.3 \mathrm{~W}$ per $1 \mathrm{~m} 2$ of the cooling surface. At higher cooling loads, a relatively large wall cooling area may be needed due to the limited permissible temperature difference between the wall surface and room temperature. For this particular wall cooling system, the surface temperature was close to the water temperature because the pipes were placed underneath the wall surface.

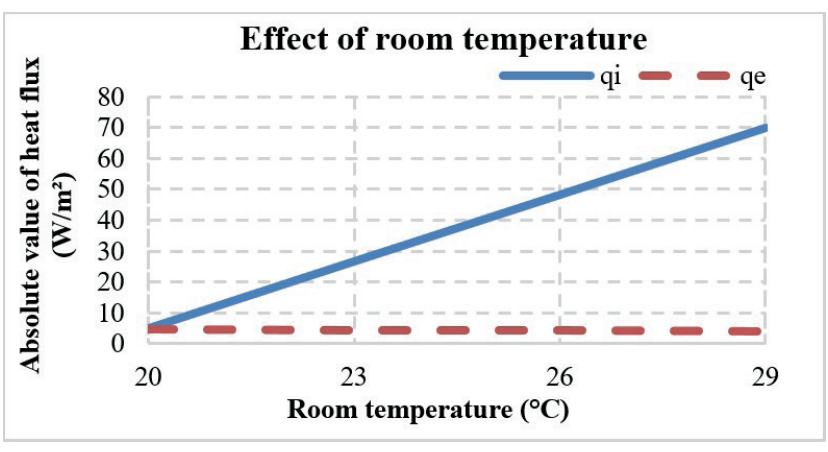

Fig. 9 Effect of room temperature on heat flux

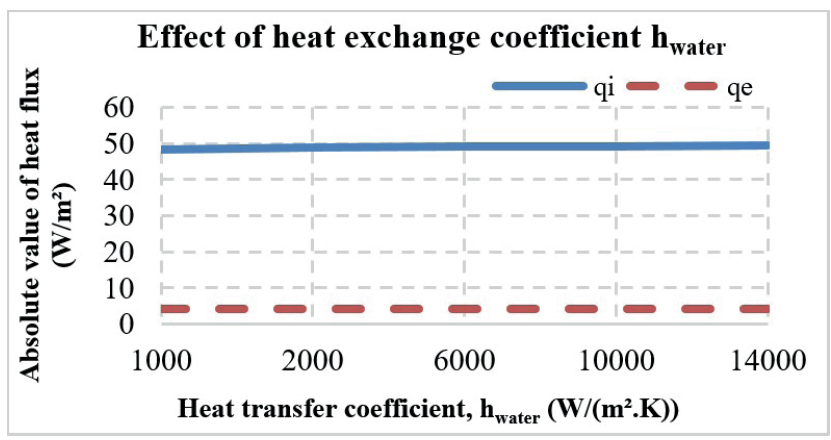

Fig. 10 Effect of heat exchange coefficient on heat flux
Table 2 [27] shows the maximum cooling capacity (CC) and coefficient of performance (COP) of an air-to-water heat pump type RLQ00 for leaving water evaporator temperature $\left(L_{W E}\right)$ of 16 to $22{ }^{\circ} \mathrm{C}$ and outdoor air temperature $\left(T_{e}\right)$ of 25 to $40{ }^{\circ} \mathrm{C}$.

For example, at the leaving water evaporator temperature $L_{W E}=18{ }^{\circ} \mathrm{C}$ and $T_{e}=30^{\circ} \mathrm{C}$, the maximum cooling capacity of the heat pump is $6.25 \mathrm{~kW}$ and the COP is 3.64 . The leaving water evaporator temperature corresponds to the water temperature supplied to the cooling pipes. At the water temperature of $18{ }^{\circ} \mathrm{C}$, the wall surface is above the dew point temperature if the relative humidity is not too high. This illustrates the fact that an air-to-water heat pump can attain reasonable COP when combined with the wall cooling system studied. A higher COP can be expected for the combination with ground- or water-source heat pump.

\section{Conclusion}

The results of the experimental measurements showed a fast thermal response of the radiant wall system. The measured heat flux at the inner wall surface in the cooling operation mode was $38.3 \mathrm{~W}$ per $\mathrm{m}^{2}$ of the cooling area.

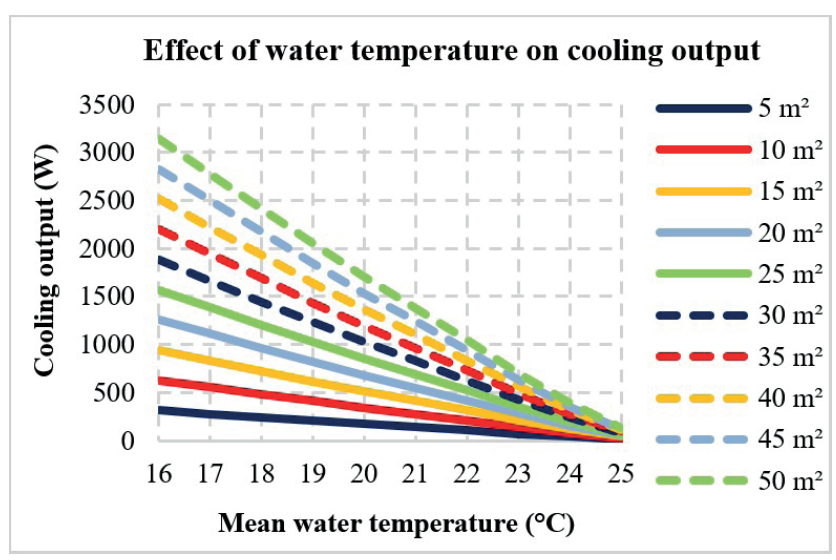

Fig. 11 Effect of mean water temperature on cooling output

Table 2 Maximum cooling capacity and COP of the heat pump [27]

\begin{tabular}{|c|c|c|c|c|c|c|c|c|}
\hline$T_{e}\left[{ }^{\circ} \mathrm{C}\right]$ & \multicolumn{2}{|c|}{25} & \multicolumn{2}{|c|}{30} & \multicolumn{2}{|c|}{35} & \multicolumn{2}{|c|}{40} \\
\hline $\begin{array}{c}\mathrm{LWE} \\
{\left[{ }^{\circ} \mathrm{C}\right]}\end{array}$ & $\begin{array}{c}\mathrm{CC} \\
{[\mathrm{kW}]}\end{array}$ & $\begin{array}{c}\text { COP } \\
{[-]}\end{array}$ & $\begin{array}{c}\mathrm{CC} \\
{[\mathrm{kW}]}\end{array}$ & $\begin{array}{c}\text { COP } \\
{[-]}\end{array}$ & $\begin{array}{c}\mathrm{CC} \\
{[\mathrm{kW}]}\end{array}$ & $\begin{array}{c}\text { COP } \\
{[-]}\end{array}$ & $\begin{array}{c}\mathrm{CC} \\
{[\mathrm{kW}]}\end{array}$ & $\begin{array}{c}\text { COP } \\
{[-]}\end{array}$ \\
\hline 16 & 6.52 & 4.10 & 6.01 & 3.43 & 5.50 & 2.88 & 4.36 & 2.53 \\
\hline 17 & 6.64 & 4.21 & 6.13 & 3.54 & 5.62 & 2.97 & 4.47 & 2.62 \\
\hline 18 & 6.75 & 4.32 & 6.25 & 3.64 & 5.75 & 3.06 & 4.58 & 2.72 \\
\hline 19 & 6.87 & 4.43 & 6.37 & 3.75 & 5.87 & 3.16 & 4.69 & 2.81 \\
\hline 20 & 7.03 & 4.58 & 6.53 & 3.87 & 6.02 & 3.27 & 4.83 & 2.92 \\
\hline 21 & 7.19 & 4.73 & 6.68 & 4.00 & 6.18 & 3.40 & 4.96 & 3.03 \\
\hline 22 & 7.36 & 4.89 & 6.84 & 4.13 & 6.33 & 3.52 & 5.10 & 3.15 \\
\hline
\end{tabular}


The corresponding temperature difference between water and hotbox (representing room) was about $8 \mathrm{~K}$. This equals about $4.8 \mathrm{~W} / \mathrm{m}^{2}$ per $1 \mathrm{~K}$ temperature difference between water and hotbox. The thermal output was measured under warm climatic conditions typical of, e.g., summer conditions in Central and Northern Europe. The surface temperature was lowest at points A-1 and D-1 at the pipe, equal to about $19.6{ }^{\circ} \mathrm{C}$, which was well above the condensation limit. This means that the cooling output could be increased by further reducing the surface temperature.

The parametric simulations of the radiant wall system were focused on the effect of sol-air temperature, room temperature, heat exchange coefficient between inner $\left(h_{i}\right)$ or outer $\left(h_{e}\right)$ wall surface and interior, heat exchange coefficient between pipe and water $\left(h_{\text {wate }}\right)$, and mean water temperature on the heat flux. The sol-air temperature had negligible effect on the cooling output due to the thermal resistance of the aerated blocks and thermal insulation. Similarly, the heat exchange coefficient between wall and exterior and between water and pipe (in the range between 1000 and $\left.14000 \mathrm{~W} /\left(\mathrm{m}^{2} . \mathrm{K}\right)\right)$ had no notable influence on the cooling

\section{References}

[1] Kassai, M. "Energy Performance Investigation of a Direct Expansion Ventilation Cooling System with a Heat Wheel", Energies, 12(22), Article number: 4267, 2019.

https://doi.org/10.3390/en12224267

[2] Nasr, M. R., Kassai, M., Ge, G., Simonson, C. J. "Evaluation of defrosting methods for air-to-air heat/energy exchangers on energy consumption of ventilation", Applied Energy 151, pp. 32-40, 2015. https://doi.org/10.1016/j.apenergy.2015.04.022

[3] Babiak, J., Olesen, B. W., Petráš, D. "Low Temperature Heating and High Temperature Cooling", REHVA Federation of European Heating, Ventilation and Air Conditioning Associations, Brussels, Belgium, 2007.

[4] Wang, X., Zheng, M., Zhang, W., Zhang, S., Yang, T. "Experimental study of a solar-assisted ground-coupled heat pump system with solar seasonal thermal storage in severe cold areas", Energy and Buildings, 42(11), pp. 2104-2110, 2010. https://doi.org/10.1016/j.enbuild.2010.06.022

[5] Romaní, J., Pérez, G., de Gracia, A. "Experimental evaluation of a cooling radiant wall coupled to a ground heat exchanger", Energy and Buildings, 129, pp. 484-490, 2016.

https://doi.org/10.1016/j.enbuild.2016.08.028

[6] Garg, H., Pandey, B., Saha, S. K., Singh, S. Banerjee, R. "Design and analysis of PCM based radiant heat exchanger for thermal management of buildings", Energy and Buildings, 169, pp. 84-96, 2018. https://doi.org/10.1016/j.enbuild.2018.03.058

[7] Kassai, M. "Heat Pump Heating System Development of Educational Building Based on Energy, Economical and Environmental Impacts", Periodica Polytechnica Mechanical Engineering, 63(3), pp. 207-213, 2019. https://doi.org/10.3311/PPme.13872 output. On the other hand, a rise of the room temperature by only $1{ }^{\circ} \mathrm{C}$ increased the thermal output by about $7 \mathrm{~W} / \mathrm{m}^{2}$, while a rise of the heat exchange coefficient between wall and room by $1 \mathrm{~W} /\left(\mathrm{m}^{2} . \mathrm{K}\right)$ increased the output by $3.4 \mathrm{~W} / \mathrm{m}^{2}$.

It was shown that coupling the wall cooling system studied with an air-to-water heat pump can positively affect the cooling capacity and COP of the heat pump. This is possible because the temperature of the water in the pipe underneath the surface is very close to the surface temperature. The high water temperature benefits the efficiency of the heat pump.

\section{Acknowledgement}

This work was supported by the Slovak Research and Development Agency under contract No. APVV-16-0126, Ministry of Education, Science, Research and Sport grants VEGA 1/0303/21 and VEGA 1/0304/21. We thank PAVJAN, s.r.o., for its help with construction of the wall, Regulaterm, s.r.o., for its help with construction of the heat and cool source, and REHAU, s.r.o. for its help with construction of the thermally active heating and cooling layer.

[8] Romaní, J., Belusko, M., Alemu, A., Cabeza, L. F., de Garcia, A., Bruno, F. "Control concepts of a radiant wall working as thermal energy storage for peak load shifting of a heat pump coupled to a PV array", Renewable Energy, 118, pp. 489-501, 2018. https://doi.org/10.1016/j.renene.2017.11.036

[9] Akbulut, U., Kincay, O., Utlu, Z. "Analysis of a wall cooling system using a heat pump", Renewable Energy, 85, pp. 540-553, 2016. https://doi.org/10.1016/j.renene.2015.07.005

[10] Masaryk, M., Mlynár, P. "Solar air-condition by ejector cooling", AIP Conference Proceedings, 2000(1), Artcile number: 020013, 2018.

https://doi.org/10.1063/1.5049920

[11] Plytaria, M. T., Bellos, E., Tzivanidis, Ch., Antonopoulos, K. A. "Numerical simulation of a solar cooling system with and without phase change materials in radiant walls of a building", Energy Conversion and Management, 188, pp. 40-53, 2019. https://doi.org/10.1016/j.enconman.2019.03.042

[12] Krajčík, M., Masaryk, M., Šimko, M., Mlynár, P. "Possibilities of combining radiant wall cooling with ejector cooling cycle powered by Fresnel solar collectors", In: 12th Nordic Symposium on Building Physics,Tallinn, Estonia, 2020, Article number: 03003. https://doi.org/10.1051/e3sconf/202017203003

[13] Harmati, N. L., Folić, R. J., Magyar, Z., Dražić, J., Kurtović-Folić, N. "Building envelope influence on the annual energy performance in office buildings", Thermal Science, 20(2), pp. 679-693, 2016. https://doi.org/10.2298/TSCI141111109H

[14] The Europen Parliament and the Council of the European Union Directive 2010/31/EU of the European Parliament and of the Council of 19 May 2010 on the energy performance of buildings. 
[15] Tomasi, R., Krajčík, M., Simone, A., Olesen, B. W. "Experimental evaluation of air distribution in mechanically ventilated residential rooms: Thermal comfort and ventilation effectiveness", Energy and Buildings, 60, pp. 28-37, 2013. https://doi.org/10.1016/j.enbuild.2013.01.003

[16] Le Dréau, J., Heiselberg, P. "Sensitivity analysis of the thermal performance of radiant and convective terminals for cooling buildings", Energy and Buildings, 82, pp. 482-491, 2014. https://doi.org/10.1016/j.enbuild.2014.07.002

[17] Krajčík, M., Šikula, O. "The possibilities and limitations of using radiant wall cooling in new and retrofitted existing buildings", Applied Thermal Engineering, 164, Article number: 114490, 2020. https://doi.org/10.1016/j.applthermaleng.2019.114490

[18] Oravec, J., Šikula, O., Krajčík, M., Arıcı, M., Mohapl, M. "A comparative study on the applicability of six radiant floor, wall, and ceiling heating systems based on thermal performance analysis", Journal of Building Engineering, 36, Article number: 102133, 2021. https://doi.org/10.1016/j.jobe.2020.102133

[19] ISO "ISO 11855-2:2012(en) Building environment design - Design, dimensioning, installation and control of embedded radiant heating and cooling systems - Part 2: Determination of the design heating and cooling capacity", The International Organization for Standardization, Geneva, Switzerland, 2012.

[20] Krajčík, M., Šimko, M., Šikula, O., Petráš, D., Szabó, D. "Thermal performance of a radiant wall heating and cooling system with pipes attached to thermally insulating bricks", Energy and Buildings, 246, p. 111122, 2021.

https://doi.org/10.1016/j.enbuild.2021.111122
[21] ASHRAE "2017 ASHRAE Handbook - Fundamentals", American Society of Heating, Refrigerating, and Air Conditioning Engineers, Atlanta, GA, USA, 2017.

[22] Šikula. O. "Manuál k softwaru CalA" (Software CalA User Manual) Tribunu, Brno, Czech Republic, 2009. (in Czech)

[23] Plášek, J. Šikula, O. "Transient Numerical Simulation of Linear Thermal Transmittance in Software CalA", Advanced Materials Research, 1041, pp. 277-280, 2014.

https://doi.org/10.4028/www.scientific.net/AMR.1041.277

[24] Patankar, S. V. "Numerical Heat Transfer and Fluid Flow", CRC Press, Boca Raton, FL, USA, 1980. https://doi.org/10.1201/9781482234213

[25] O'Callaghan, P. W., Probert, S. D. "Sol-air temperature", Applied Energy, 3(4), pp. 307-311, 1977. https://doi.org/10.1016/0306-2619(77)90017-4

[26] Šimko, M., Krajčík, M., Šikula, O., Šimko, P., Kalús, D. "Insulation panels for active control of heat transfer in walls operated as space heating or as a thermal barrier: Numerical simulations and experiments", Energy and Buildings, 158, pp. 135-146, 2018. https://doi.org/10.1016/j.enbuild.2017.10.019

[27] Daikin [online] Available at: https://www.daikin.sk/ [Accessed: 08 April 2021] 